\title{
ATIVIDADE ANTIOXIDANTE DE FRUTOS DE QUATRO CULTIVARES DE PESSEGUEIRO ${ }^{1}$
}

\author{
CLÁUDIA MENDES DOS SANTOS², CELESTE MARIA PATTO DE ABREU ${ }^{3}$, \\ JULIANA MESQUITA FREIRE ${ }^{4}$, ANGELITA DUARTE CORREA ${ }^{5}$
}

RESUMO- Esforços são empregados para identificar plantas com teores de antioxidantes que conferem benefícios à saúde. A capacidade antioxidante do pêssego deve-se aos compostos fenólicos, vitamina $\mathrm{C} \mathrm{e}$ carotenoides. O objetivo deste trabalho foi caracterizar quatro cultivares de pessegueiro (Aurora, Biuti, Diamante e Douradão) em relação à capacidade antioxidante, determinando o teor dos compostos antioxidantes relacionados a essa atividade. Os frutos foram separados em dois grupos: sem armazenamento e armazenados por cinco dias à temperatura ambiente. Foram determinados os teores de vitamina $\mathrm{C}$, carotenoides, compostos fenólicos e a capacidade antioxidante, pelos métodos DPPH e $\beta$-caroteno/ácido linoleico. As quatro cultivares mostraram-se ricas em substâncias antioxidantes, porém a intensidade dessa ação foi diferenciada entre elas. A cultivar Biuti apresentou maior teor das substâncias analisadas e maior atividade antioxidante em relação às outras cultivares. Foi observado que o potencial antioxidante dos frutos de pêssego aumentou durante o período de armazenamento.

Termos para indexação: Prunus persica, compostos fenólicos, vitamina C, carotenoides.

\section{ANTIOXIDANT ACTIVITY OF FRUITS OF FOUR PEACH CULTIVARS}

\begin{abstract}
Efforts have been spent in order to identify plants with antioxidant levels that provide health benefits. The antioxidant capacity of peach is due to phenolic compounds, vitamin $\mathrm{C}$ and carotenoids. This study aimed to characterize four peach cultivars (Aurora, Biuti, Diamante and Douradão), in relation to the antioxidant capacity, determining the content of antioxidant compounds related to this activity. The fruits were separated into two groups: not stored and stored for five days at room temperature. The contents of vitamin $\mathrm{C}$, carotenoids, phenolic compounds and the antioxidant capacity were determined by DPPH and $\beta$-carotene/linoleic acid methods. All the cultivars proved to be rich in antioxidant substances; however, the intensity of this action was different among them. Cultivar Biuti presented highest levels of the analyzed substances and higher antioxidant activity compared to other cultivars. It was possible to observe that the antioxidant potential of peach fruits increased during the storage period.
\end{abstract}

Index terms: Prunus persica, phenolic compounds, vitamin C, carotenoids.

\section{INTRODUÇÃO}

A natureza fornece-nos um número expressivo de substâncias orgânicas, sendo os vegetais os principais contribuintes. O potencial de fornecimento dessas substâncias deve-se à capacidade de esses organismos biossintetizarem os mais diversos tipos de estruturas moleculares. Essas substâncias participam diretamente das interações bioquímicas entre as plantas e os vários organismos vivos no sistema ambiental.

Existe clara tendência mundial de que as pessoas passem a se preocupar mais com a saúde e o bem-estar, ampliando, dessa forma, o consumo de frutas por seu valor nutricional, alto teor de fibras, vitamina $\mathrm{C}$ e carotenoides. Maior atenção tem sido dada aos alimentos conhecidos como funcionais, (NEVES, 2012) uma vez que evidências epidemiológicas têm demonstrado que o consumo regular de vegetais com propriedades funcionais está associado à redução da mortalidade e da morbidade por algumas doenças crônicas não transmissíveis (VIEIRA et al., 2011). O efeito protetor exercido por esses alimentos tem sido atribuído à presença de fitoquímicos com ação antioxidante. Antioxidantes e a correlação entre a sua ocorrência e a qualidade dos vegetais estão sendo amplamente investigados (DI VAIO et al., 2008).

O pêssego (Prunus persica L.) é uma das frutas mais cultivadas em regiões de clima tempera-

'(Trabalho 253-12). Recebido em: 13-09-2012. Aceito para publicaçaõ em: 07-06-2013.

${ }^{2}$ Doutoranda em Agroquímica. Universidade Federal de Lavras - UFLA. Email: claumsantos@yahoo.com.br

${ }^{3}$ Professora Associada. Departamento de Química, Universidade Federal de Lavras - UFLA. Email: celeste@dqi.ufla.br

${ }^{4}$ Doutora em Agroquímica. Universidade Federal de Lavras - UFLA. Email: mesquitafreire@yahoo.com.br

${ }^{5}$ Professora Associada. Departamento de Química, Universidade Federal de Lavras - UFLA. Email: angelita@dqi.ufla.br 
do e subtropical do mundo. Devido à sua aceitabilidade e ao alto consumo pela população, contribui para o aumento da ingestão de antioxidante na dieta humana. Os índices de substâncias antioxidantes em pêssegos podem variar entre cultivar, fatores genéticos e ambientais. Além disso, como os frutos são colhidos antes da fase de amadurecimento, o teor desses antioxidantes pode ser afetado pelo estádio de maturação na colheita, pelas técnicas de armazenamento e pelo tempo decorrido entre a colheita e o consumo (SANTOS, 2011).

Os polifenois são as principais fontes de capacidade antioxidante em pêssegos, embora a vitamina $\mathrm{C}$ e os carotenoides também contribuam para isso (CANTÍN; MORENO; GORGOCENA, 2009). A diversidade genética reflete também em sua capacidade antioxidante. De fato, muitos resultados encontrados em estudos com diferentes cultivares de pêssego demonstram que o genótipo desempenha um papel fundamental na capacidade antioxidante desses frutos (SANTOS, 2011).

Este trabalho foi realizado com o objetivo de caracterizar quatro cultivares de pessegueiro em relação à capacidade antioxidante e determinar os teores dos compostos relacionados a essa atividade.

\section{MATERIAL E MÉTODOS}

O trabalho foi conduzido no Laboratório de Bioquímica, no Departamento de Química da Universidade Federal de Lavras (UFLA).

Os frutos de pêssegos das cultivares Aurora, Biuti, Diamante e Douradão foram colhidos pela manhã, em estádio de maturação próprio para consumo, adquiridos nas cidades de Lavras-MG, e Nepomuceno-MG.

Foram selecionados 32 frutos de cada cultivar, padronizados quanto ao estádio de maturação, ao tamanho e à ausência de danos mecânicos, e divididos em dois grupos: sem armazenamento e armazenados por cinco dias, à temperatura ambiente $\left(25^{\circ} \mathrm{C} \pm 0,87^{\circ} \mathrm{C}\right.$ e $\left.69,5 \% \pm 2,35 \% \mathrm{UR}\right)$. Os frutos dos dois grupos foram descascados, e as polpas, picadas, liofilizadas, trituradas em moinho e armazenadas em potes hermeticamente fechados para a realização das análises químicas.

Utilizou-se o delineamento experimental inteiramente casualizado (DIC), em esquema fatorial $4 \times 2$, sendo o primeiro fator constituído pelas quatro cultivares (Diamante, Biuti, Douradão e Aurora), e o segundo fator, pelos dias de análises (dia da colheita e 5 dias de armazenamento), com 4 repetições de 4 frutos para cada tratamento. Os resultados foram submetidos à análise de variância, por meio do programa Sisvar (FERREIRA, 2011), sendo as médias comparadas pelo teste Tukey, a 5\% de probabilidade.

O teor de $\beta$-caroteno foi determinado pelo método colorimétrico descrito por Nagata e Yamashita (1992). A vitamina $C$ foi determinada pelo método colorimétrico descrito por Strohecker e Henning (1967). A extração dos compostos fenólicos foi realizada com metanol a $50 \%$, em refluxo, por três vezes consecutivas, a $80^{\circ} \mathrm{C}$, e os extratos, reunidos e evaporados a $25 \mathrm{~mL}$. Após a extração, os compostos fenólicos totais foram quantificados pelo método de Folin-Denis (AOAC, 2012). Os resultados foram expressos em mg de ácido tânico $\mathrm{g}^{-1}$ de amostra. A análise da atividade antioxidante foi feita pelos métodos DPPH e $\beta$-caroteno/ácido linoleico. Para o método DPPH, a extração dos antioxidantes foi realizada segundo Rufino et al. (2007). Utilizaram-se $20 \mathrm{~mL}$ do líquido extrator (metanol 50\%/acetona $70 \%$ ) para 1 grama da amostra de pêssego liofilizada. Os extratos foram submetidos à agitação, por 60 minutos, à temperatura ambiente e ao abrigo da luz. Posteriormente, foram centrifugados, por 15 minutos, a $25.000 \mathrm{~g}$, e o sobrenadante, transferido para balão volumétrico de $25 \mathrm{~mL}$; e o volume, completado com água destilada. A capacidade de sequestrar o radical 1,1-difenil-2-picrilhidrazil foi realizada segundo método descrito por Thaipong et al. (2006), com modificações. Foram preparadas quatro diluições dos extratos de polpa liofilizada de pêssego. Alíquotas de $0,1 \mathrm{~mL}$ de cada diluição foram adicionadas a $3,9 \mathrm{~mL}$ da solução de DPPH em metanol (0,06 mM), após agitação em vórtex, e os tubos foram deixados em repouso ao abrigo da luz. Ao final de 30 minutos, a absorbância foi medida a $515 \mathrm{~nm}$, e a capacidade de sequestrar o radical, expressa em percentual, calculada em relação ao controle (sem antioxidante), segundo a expressão a seguir:

\% sequestros $=$ Absorbância do controle - Absorbância da amostra $\times 100 \%$

Absorbância do controle

Por meio de uma equação da reta para cada amostra do extrato de pêssego, foram calculadas as concentrações necessárias para inibir $50 \%$ do radical DPPH'. O antioxidante sintético butil-hidroxitolueno (BHT) foi utilizado como padrão e submetido às mesmas condições.

A extração dos antioxidantes para o método $\beta$-caroteno/ácido linoleico foi realizada segundo Rufino et al. (2006). Utilizaram-se $20 \mathrm{~mL}$ do líquido extrator (metanol 50\%/acetona $70 \%$ ) para $1 ; 0,5$ e 0,25 gramas da amostra de pêssego liofilizada. Os extratos foram submetidos à agitação por 60 minu- 
tos, à temperatura ambiente e ao abrigo da luz. Posteriormente, foram centrifugados, por 15 minutos, a $25.000 \mathrm{~g}$, e o sobrenadante, transferido para balão volumétrico de $25 \mathrm{~mL}$; e o volume, completado com água destilada.

Para o preparo da solução sistema de $\beta$-caroteno/ácido linoleico, utilizou-se de $50 \mu \mathrm{L}$ de $\beta-$ -caroteno diluído em clorofórmio $(20 \mathrm{mg} / \mathrm{mL})$, aos quais se adicionaram $40 \mu \mathrm{L}$ de ácido linoleico e 530 $\mu \mathrm{L}$ de Tween 20 , e $1 \mathrm{~mL}$ de clorofórmio. O clorofórmio foi evaporado em rota-evaporador, e $100 \mathrm{~mL}$ de água saturada de oxigênio foram acrescentados e agitados até que a solução apresentasse uma coloração amarelo-alaranjada. Em tubos de ensaio, 5 $\mathrm{mL}$ dessa solução/sistema foram adicionados a 0,4 $\mathrm{mL}$ de cada diluição dos extratos empregados para o teste. Foram preparados três tubos-controle contendo, em cada um, $5 \mathrm{~mL}$ da solução/sistema com $0,4 \mathrm{~mL}$ do padrão Trolox ${ }^{\circledR}$. Após homogeneização, foram feitas leituras em espectrofotômetro a 470 $\mathrm{nm}$, utilizando-se de água para calibração. Os tubos foram colocados em banho-maria a $40{ }^{\circ} \mathrm{C}$, e leituras sequenciais foram feitas após 1 hora e 2 horas.

Foi avaliada a percentagem de inibição da oxidação, em que a redução da absorbância do sistema sem antioxidante (Equação 1) é considerada como $100 \%$ de oxidação.

Redução de absorbância = Abs inicial - Abs final (Eq. 1)

Correlacionou-se a queda da leitura de absorbância das amostras com o sistema e estabeleceu-se a percentagem de oxidação (Equação 2). A percentagem de proteção contra a oxidação lipídica é dada, subtraindo-se a percentagem de oxidação de cada amostra, de 100 (Equação 3).
\% oxidação $=[($ redução Abs) amostra x 100] (Eq.2) (redução Abs)sistema

$\%$ proteção $=100-(\%$ Oxidação $)$

A ação antioxidante de cada amostra foi verificada, comparando-se com a atividade antioxidante da substância utilizada como padrão.

\section{RESULTADOS E DISCUSSÃO}

Entre os frutos das cultivares analisadas, pôde-se avaliar que os pêssegos da cultivar Biuti apresentaram maior teor de carotenoides para os frutos armazenados $\left(5,75 \mathrm{mg} \beta\right.$-caroteno $\left.100 \mathrm{~g}^{-1}\right)$. Já para os frutos sem armazenamento, as cultiva- res Biuti e Diamante apresentaram os maiores valores $\left(1,75\right.$ e $1,63 \mathrm{mg} \beta$-caroteno $100 \mathrm{~g}^{-1}$, respectivamente) (Tabela 1$)$. Os teores de carotenoides nos frutos armazenados foram maiores para todas as cultivares, quando comparados aos frutos sem armazenamento, devido ao amadurecimento e a uma baixa UR do ambiente de armazenamento (em torno de $70 \%$ ), o que pode ter causado perda de água do fruto, contribuindo para maior concentração de carotenoides. Sentanin e Rodriguez-Amaya (2007) analisaram o teor de carotenoides em cultivares de pêssego Diamante, Coral e Xiripá, encontrando, respectivamente, 0,$4 ; 0,03$ e $0,06 \mathrm{mg}$ de $\beta$-caroteno $100 \mathrm{~g}^{-1}$. Os valores encontrados neste trabalho para a cultivar Diamante, sem armazenamento $(1,6 \mathrm{mg}$ $\left.100 \mathrm{~g}^{-1}\right)$ e com armazenamento (3,29 mg $\left.100 \mathrm{~g}^{-1}\right)$, foram superiores ao encontrado por esses autores para essa cultivar. Essa diferença pode estar relacionada com o local de cultivo e o clima, influenciando no teor desta substância. Para as outras três cultivares de pêssego (Aurora, Biuti e Douradão), não foram encontrados dados na literatura.

Para a vitamina $\mathrm{C}$, as cultivares Biuti e Aurora foram as que apresentaram o maior teor nos frutos sem armazenamento $(23,28$ e $22,28 \mathrm{mg}$ de ácido ascórbico $100 \mathrm{~g}^{-1}$ de amostra, respectivamente), sendo a 'Biuti' a cultivar com maior teor de vitamina $\mathrm{C}$ nos frutos armazenados $(28,01 \mathrm{mg}$ de ácido ascórbico $100 \mathrm{~g}^{-1}$ de amostra) (Tabela 1). Entretanto, nas cultivares, os valores variaram, em média, de 17 a $28 \mathrm{mg}$ de vitamina $\mathrm{C} 100 \mathrm{~g}^{-1}$, podendo o pêssego ser considerado uma fonte razoável deste nutriente, uma vez que a necessidade diária recomendada é de $60 \mathrm{mg} /$ dia (BRASIL, 1998). Verificou-se que o teor de vitamina $C$ foi maior para as cultivares Biuti e Douradão após o armazenamento. A manutenção ou a elevação dos níveis de ácido ascórbico durante o armazenamento pode ser decorrente das transformações bioquímicas que ocorrem no período de armazenamento do fruto in natura. Segantini et al. (2012), quantificando os teores de vitamina $\mathrm{C}$ em cinco cultivares de pêssegos de polpa amarela, obtiveram valores entre 7,95 e

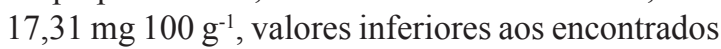
para as quatro cultivares estudadas neste trabalho. $\mathrm{A}$ variação do conteúdo de vitamina $\mathrm{C}$ dos frutos depende de muitos fatores, incluindo as variedades de cultivares, genética, estádio de maturação, tratos culturais, tipo de solo, condições climáticas e época de colheita. Também a duração e as condições de armazenamento pós-colheita podem influenciar de forma decisiva no teor deste constituinte (SILVA et al., 2006).

Verificou-se que os teores de compostos fe- 
nólicos aumentaram com o período de armazenamento, para as cultivares Aurora, Biuti e Douradão (Tabela 1). As cultivares diferiram entre si e entre os tempos de armazenamento, e a cultivar Biuti apresentou o maior teor de compostos fenólicos, tanto para os frutos armazenados $\left(14,25 \mathrm{mg} \mathrm{g}^{-1}\right)$ como para os sem armazenamento $\left(12,83 \mathrm{mg} \mathrm{g}^{-1}\right)$. Os teores mais baixos foram observados para a cultivar Aurora, nos frutos sem armazenamento $(2,60 \mathrm{mg}$ $\left.\mathrm{g}^{-1}\right)$ e nos armazenados $\left(3,41 \mathrm{mg} \mathrm{g}^{-1}\right)$. Esses resultados mostraram que há um aumento no conteúdo de compostos fenólicos durante o armazenamento, que pode ser devido à hidrólise desses compostos ligados à parede celular. Os teores encontrados para as quatro cultivares, neste trabalho, estão dentro da faixa observada por Di Vaio et al. (2008). Estes autores, estudando o teor de compostos fenólicos em seis cultivares de pêssego, obtiveram valores entre $5,96 \mathrm{mg} \mathrm{g}^{-1}$ e 7,28 $\mathrm{mg} \mathrm{g}^{-1}$, para frutos sem armazenamento, e de $6,56 \mathrm{mg} \mathrm{g}^{-1}$ a $8,21 \mathrm{mg} \mathrm{g}^{-1}$, para frutos armazenados por 7 dias sob refrigeração.

O potencial dos extratos de pêssego em sequestrar radicais livres foi expresso como a concentração do extrato necessária para inibir a oxidação do radical DPPH em 50\% (Tabela 2). As substâncias antioxidantes presentes nos extratos reagem com o $\mathrm{DPPH}^{\circ}$, que é um radical livre e, dessa forma, estabiliza-o. O extrato que apresenta alto potencial em sequestrar radicais livres tem baixo valor de $\mathrm{IC}_{50}$ (concentração necessária para inibir $50 \%$ do radical livre formado). Dessa forma, uma pequena quantidade de extrato é capaz de decrescer a concentração inicial do radical $\mathrm{DPPH}^{*}$ em $50 \%$. Para efeito de comparação, utilizou-se o antioxidante sintético BHT (Butil hidroxitolueno), que apresen-

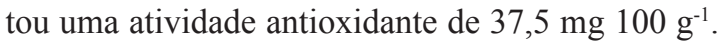
As cultivares de pêssego Aurora, Biuti, Diamante e Douradão apresentaram atividade antioxidante, porém a intensidade dessa ação foi diferente entre elas. A cultivar Biuti armazenada exibiu a melhor ação antioxidante, melhor capacidade de sequestrar o radical $\mathrm{DPPH}^{\circ}$, com o menor valor de $\mathrm{IC}_{50},(17,0$ mg $100 \mathrm{~g}^{-1}$ ), concordando com os maiores teores de carotenoides, vitamina $\mathrm{C}$ e compostos fenólicos (Tabela 1) encontrados para esta cultivar. A atividade antioxidante de cinco cultivares de pêssegos de polpa amarela, estudadas por Gil et al. (2002), variou de 10,4 a $43,2 \mathrm{mg} 100 \mathrm{~g}^{-1}$. Segantini et al. (2012) encontraram valores da atividade antioxi-

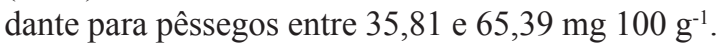
Segundo Tavarini et al. (2008), o genótipo (cultivar) influencia diretamente sobre a determinação da capacidade antioxidante total nas frutas de pêssego. Gil et al. (2002) relataram que a capacidade antio- xidante total varia em função da cultivar e também do porta-enxerto.

Entre as concentrações dos extratos testados, no método $\beta$-caroteno/ácido linoleico, a de $10 \mathrm{~g} \mathrm{~L}^{-1}$ foi a concentração com valores maiores de inibição de oxidação. Para a cultivar Biuti, observaram-se os maiores teores de inibição da oxidação lipídica, tanto para os frutos armazenados $(92,96 \%)$ como não para os armazenados $(91,48 \%)$ (Tabela 2). Para efeito de comparação, utilizou-se o antioxidante sintético Trolox, que apresentou uma \% de inibição de 93,31. Todas as cultivares apresentaram menor atividade antioxidante que o Trolox ${ }^{\circledR}$, porém bem próximo à desse controle. Muitos autores relatam o potencial antioxidante acima de $70 \%$ como ótimo para a inibição da oxidação lipídica. As cultivares estudadas neste trabalho alcançaram atividade antioxidante acima de $70 \%$, apresentando alto potencial de inibição da oxidação lipídica. Em estudos com bagaços de frutas de resíduos industriais, Melo et al. (2011) encontraram maiores percentuais de inibição para engaço de uva tinta (72,13\%), e os menores valores foram observados para o bagaço de goiaba (19,72\%). Os resultados da avaliação da capacidade antioxidante de frutas comercializadas em Recife-PE, em um trabalho de Melo et al. (2008), variaram de 3,33 a 61,03\% e de 3,89 a $67,25 \%$ de inibição para o extrato aquoso e acetônico, respectivamente. Em função do percentual de inibição exibido, os autores relataram a pinha (extrato aquoso) e a goiaba (extrato acetônico) como frutas com moderada capacidade antioxidante (50 a $70 \%)$.

Devido aos diferentes tipos de radicais livres e as suas diferentes formas de atuação nos organismos vivos, dificilmente existirá um método simples e universal pelo qual a atividade antioxidante possa ser medida precisa e quantitativamente. A utilização de vários métodos para avaliar a atividade antioxidante permite maior precisão na indicação do potencial antioxidante da fruta. Fatores como o método analítico de extração, condições climáticas, origem geográfica e constituintes químicos são os principais responsáveis pelos mais diferentes resultados encontrados na literatura quanto à atividade antioxidante dos alimentos e devem ser levados em consideração como comparação de resultados, para que sejam válidos (ALVES et al., 2010). 
TABELA 1- Teores de vitamina C, carotenoides e compostos fenólicos de quatro cultivares de pêssego sem armazenamento (S.A.) e com armazenamento de cinco dias (C.A.), sob condições ambientais $\left(25^{\circ} \mathrm{C} \pm 0,87^{\circ} \mathrm{C}\right.$ e $\left.69,5 \% \pm 2,35 \% \mathrm{UR}\right)$.

Vitamina C Carotenoides Fenólicos

Cultivar (mg ácido ascórbico $\left.100 \mathrm{~g}^{-1}\right) \quad\left(\mathrm{mg} \beta\right.$-caroteno $\left.100 \mathrm{~g}^{-1}\right) \quad$ (mg ácido tânico $\left.\mathrm{g}^{-1}\right)$

\begin{tabular}{ccccccc} 
& S. A. & C.A. & S. A. & C.A. & S. A. & C.A. \\
\hline Aurora & $22,28 \mathrm{aA}$ & $22,40 \mathrm{bA}$ & $0,26 \mathrm{bB}$ & $1,67 \mathrm{cA}$ & $2,60 \mathrm{~dB}$ & $3,41 \mathrm{cA}$ \\
Biuti & $23,28 \mathrm{aB}$ & $28,01 \mathrm{aA}$ & $1,75 \mathrm{aB}$ & $5,75 \mathrm{aA}$ & $12,83 \mathrm{aB}$ & $14,25 \mathrm{aA}$ \\
Diamante & $18,13 \mathrm{bA}$ & $17,72 \mathrm{cA}$ & $1,63 \mathrm{aB}$ & $3,29 \mathrm{bA}$ & $6,21 \mathrm{bA}$ & $3,67 \mathrm{cB}$ \\
Douradão & $17,57 \mathrm{bB}$ & $22,76 \mathrm{bA}$ & $0,34 \mathrm{bB}$ & $2,78 \mathrm{cA}$ & $3,88 \mathrm{cB}$ & $4,90 \mathrm{bA}$ \\
\hline CV (\%) & \multicolumn{2}{c}{2,86} & \multicolumn{3}{c}{14,40} & 4,71
\end{tabular}

Médias seguidas da mesma letra minúscula nas colunas não diferem entre si, e médias seguidas da mesma letra maiúscula nas linhas não diferem entre si, pelo teste de Tukey, a $5 \%$ de probabilidade $(n=4)$.

TABELA 2- Atividade antioxidante pelo método DPPH e $\beta$-caroteno/ácido linoleico de quatro cultivares de pêssego sem armazenamento (S.A.) e com armazenamento de cinco dias (C.A.), sob condições ambientais $\left(25^{\circ} \mathrm{C} \pm 0,87^{\circ} \mathrm{C}\right.$ e $\left.69,5 \% \pm 2,35 \% \mathrm{UR}\right)$.

\begin{tabular}{ccccc}
\hline \multirow{2}{*}{ Cultivar } & \multicolumn{2}{c}{ DPPH $\left(\mathrm{IC}_{50 \%} \mathrm{mg} 100 \mathrm{~g}^{-1}\right)$} & \multicolumn{2}{c}{$\beta$-caroteno/ácido linoleico (\% de inibição) } \\
\cline { 2 - 5 } & S.A. & C.A. & S. A. & C.A. \\
\hline Aurora & $612,5 \mathrm{aA}$ & $365,0 \mathrm{aB}$ & $88,16 \mathrm{bA}$ & $89,42 \mathrm{bA}$ \\
Biuti & $52,5 \mathrm{dA}$ & $17,0 \mathrm{~dB}$ & $91,48 \mathrm{aB}$ & $92,96 \mathrm{aA}$ \\
Diamante & $187,5 \mathrm{cA}$ & $170,0 \mathrm{cA}$ & $87,21 \mathrm{bB}$ & $89,15 \mathrm{bA}$ \\
Douradão & $270,0 \mathrm{bA}$ & $230,0 \mathrm{bB}$ & $85,39 \mathrm{cB}$ & $87,30 \mathrm{cA}$ \\
\hline CV $(\%)$ & \multicolumn{3}{c}{10,90} & \\
\hline
\end{tabular}

Médias seguidas da mesma letra minúscula nas colunas não diferem entre si, e médias seguidas da mesma letra maiúscula nas linhas não diferem entre si, pelo teste de Tukey, a $5 \%$ de probabilidade $(n=4)$.

\section{CONCLUSÃO}

Nas condições em que o experimento foi realizado, pode-se concluir que as quatro cultivares de pêssego se mostram ricas em compostos fenólicos, vitamina $\mathrm{C}$ e carotenoides, apresentando elevada capacidade antioxidante. Porém, a intensidade dessa ação é diferenciada entre elas.

Dentre as cultivares estudadas, a 'Biuti' destaca com o maior teor de todas as substâncias bioativas analisadas e apresenta maior atividade antioxidante.

O potencial antioxidante dos frutos de pêssego aumenta durante o período de armazenamento.

\section{REFERÊNCIAS}

ALVES, C. Q.; DAVID, J. M.; DAVID, J. P.; BAHIA, M. V.; AGUIAR, R. M. Métodos para determinação de atividade antioxidante in vitro em substratos orgânicos. Química Nova, São Paulo, v.33, n.10, p.2202-2210, 2010.
AOAC - Association of Official Analytical Chemistry. Official methods of analysis. $19^{\text {th }} \mathrm{ed}$. Gaithersburg, 2012. 3000p.

BRASIL. Portaria SVS/MS no 33 , de 13 de janeiro de 1998. Tabelas de ingestão diária recomendada (IDR). Diário Oficial da União, Brasília-DF, 16 jan. 1998. Seção 1, parte 1.

CANTÍN, C. M.; MORENO, M.A.; GOGORCENA, Y. Evaluation of the antioxidant capacity, phenolic compounds, and vitamin $\mathrm{C}$ content of different peach and nectarine[Prunus persica (L.) Batsch] breeding progenies. Journal of Agricultural and Food Chemistry, Chicago, v. 57, p. 4586-4592, 2009.

DI VAIO, C.; GRAZIANI, G.; MARRA, L.; CASCONE, A.; RITIENI, A. Antioxidant capacities, carotenoids and polyphenols evaluation of fresh and refrigerated peach and nectarine cultivars from Italy. European Food Research and Technology, Berlin, v. 227, p. 1225-1231, 2008. 
FERREIRA, D. F. Sisvar: a computer statistical analysis system. Ciência e Agrotecnologia, Lavras, v.35, n.6, p.1039-1042, 2011.

GIL, M. I.; TOMÁS-BARBERÁN, F. A.; HESSPIERCE, B.; KADER, A. A. Antioxidant capacities, phenolic compounds, carotenoids, and vitamin $\mathrm{C}$ contents of nectarine, peach, and plum cultivars from California. Journal of Agricultural and Food Chemistry, Chicago, v. 50, n. 17, p. 49764982, 2002.

MELO, E.A.; MACIEL, M. I. S.; LIMA, V. L.A. G.; NASCIMENTO, R. J. Capacidade antioxidante de frutas. Revista Brasileira de Ciências Farmacêuticas, São Paulo, v. 44, n.2, p. 193-201, 2008.

MELO, P. S.; BERGAMASCHI, K. B.; TIVERON, A. P.; MASSARIOLI, A. P.; OLDONI, T. L. C.; ZANUS, M. C.; PEREIRA, G. E.; ALENCAR, S. M. Composição fenólica e atividade antioxidante de resíduos agroindustriais. Ciência Rural, Santa Maria, v. 41, n.6, p. 1088-1093, 2011.

NAGATA, M.; YAMASHITA, I. Simple method for simultaneous determination of cholorophyll and carotenoids in tomatoes fruit. Nippon Shokuhin Kogyo Gakkaishi, Tokyo, v. 39, n. 10, p. 925-928, 1992.

NEVES, L. C. Frutos - O remédio do futuro. Revista Brasileira de Fruticultura, Jaboticabal, v. 34, n.4. p. i, 2012.

RUFINO, M. S. M.; ALVES, R. E.; BRITO, E. S.; MANCINI FILHO, J.; MOREIRA, A. V. B. Metodologia cientifica: determinação da atividade antioxidante total em frutas no sistema b-caroteno/ ácido linoleico. Fortaleza: Embrapa, 2006. (Comunicado Técnico).

RUFINO, M. S. M.; ALVES, R. E.; BRITO, E. S.; MORAIS, S. M.; SAMPAIO, C. G.; PÉREZ-JIMÉNEZ, J.; SAURA-CALIXTO, F. D. Metodologia científica: determinação da atividade antioxidante total em frutas pela captura do radical livre DPPH. Fortaleza: Embrapa, 2007. (Comunicado Técnico).
SANTOS, R. O. Capacidade antioxidante de pêssegos de polpa amarela em três estádios de maturação e minimamente processados. 2011. Dissertação (Mestrado em Ciência e Tecnologia Agroindustrial) - Universidade Federal de Pelotas, Pelotas, 2011.

SEGANTINI, D. M.; LEONEL, S.; LIMA, G. P. P.; COSTA, S. M.; RAMOS, A. R. P. Caracterização da polpa de pêssegos produzidos em São ManuelSP. Ciência Rural, Santa Maria, v.42, n.1, p.52-57, 2012.

SENTANIN, M. A.; RODRIGUEZ-AMAYA, D B. Teores de carotenoides em mamão e pêssego determinados por cromatografia líquida de alta eficiência. Ciência e Tecnologia de Alimentos, Campinas, v.27, n.1, p.13-19, 2007.

SILVA, P. T.; LOPES, M. L. M.; VALENTEMESQUITA, V. L. Efeito de diferentes processamentos sobre o teor de ácido ascórbico em suco de laranja utilizado na elaboração de bolo, pudim e geleia. Ciência e Tecnologia de Alimentos, Campinas, v.26, n.3, p.678-682, 2006.

STROHECKER, R.; HENNING, H. M. Analisis de vitaminas: métodos comprobados. Madrid: Paz Montalvo, 1967. $428 \mathrm{p}$.

TAVARINI, S.; DEGL'INNOCENTI, E.; REMORINI, D.; MASSAI, R.; GUIDI, L. Preliminary characterisation of peach cultivars for their antioxidant capacity. International Journal of Food Science and Technology, Hoboken, v.43, p.810-815, 2008.

THAIPONG, K.; BOONPRAKOB, U.; CROSBY, K.; CISNEROS-ZEVALLOS, L.; BYRNE, D. H. Comparison of ABTS, DPPH, FRAP and ORAC assays for estimating antioxidant activity from guava fruit extracts. Journal of Food Composition and Analysis, San Diego, v.19, p.669-675, 2006.

VIEIRA, L. M.; SOUSA, M. S. B.; MANCINIFILHO, J.; LIMA, A. Fenólicos totais e capacidade antioxidante in vitro de polpas de frutos tropicais. Revista Brasileira de Fruticultura, Jaboticabal, v.33, n.3, p.888-897, 2011. 